\title{
Ultrasound Guided Erector Spinae Plane Block: a safe alternative analgesic tool against chronic post-thoracotomy pain!
}

\author{
Sílvia S. J. ${ }^{1}$, Pedro A. ${ }^{2}$, Raquel L. ${ }^{1}$, Jorge C. ${ }^{1}$, João S. D. ${ }^{1}$ \\ ${ }^{1}$ Departamento de Anestesiologia e Cuidados Intensivos, Centro Hospitalar de Setúbal \\ 2 Departamento de Radiologia, Centro hospitalar de Lisboa Central
}

\section{INTRODUCTION}

International Association for the Study of Pain (IASP) and recent studies, defined Chronic post-thoracotomy pain (CPTP) following thoracic surgery as pain persisting for at least 3 months after toracothomy.

\section{Surgical factors:}

- Posterolateral approach to thoracotomy;

- Muscle-sparing approaches $\rightarrow$ excessive rib retraction, fracture, dislocation, costovertebral disruption, and damage to the intercostal nerves because of reduced surgical field;

- Video-assisted thoracoscopic surgery (VATS) $\rightarrow$ incidence of CPTP is similar to open thoracotomy.

Individual factors include age below 60 years old, female gender, hypertension, lack of PCA for post-operative analgesia, and duration of chest tube drainage superior to 4 days.

There are some conservative and interventional treatment options that can be chosen.

There is a novel Ultrasound Guided Erector Spinae Plane

Block (USESPB).

- Sitting position

- High-frequency linear ultrasound transducer in a longitudinal orientation $3 \mathrm{~cm}$ lateral to the $T 5$ spinous process

- Three muscles are identified superficial to the hyperechoic transverse process shadow as follows: trapezius, rhomboid major, and erector spinae.

- An 8-cm and 22-gauge block needle

- Cephalad-to-caudad direction

- Tip in the interfascial plane between rhomboid major and erector spinae muscles

- Visible linear spread of fluid between them (Fig. 1)

- A total of $20 \mathrm{~mL}$ of local anesthetic is injected
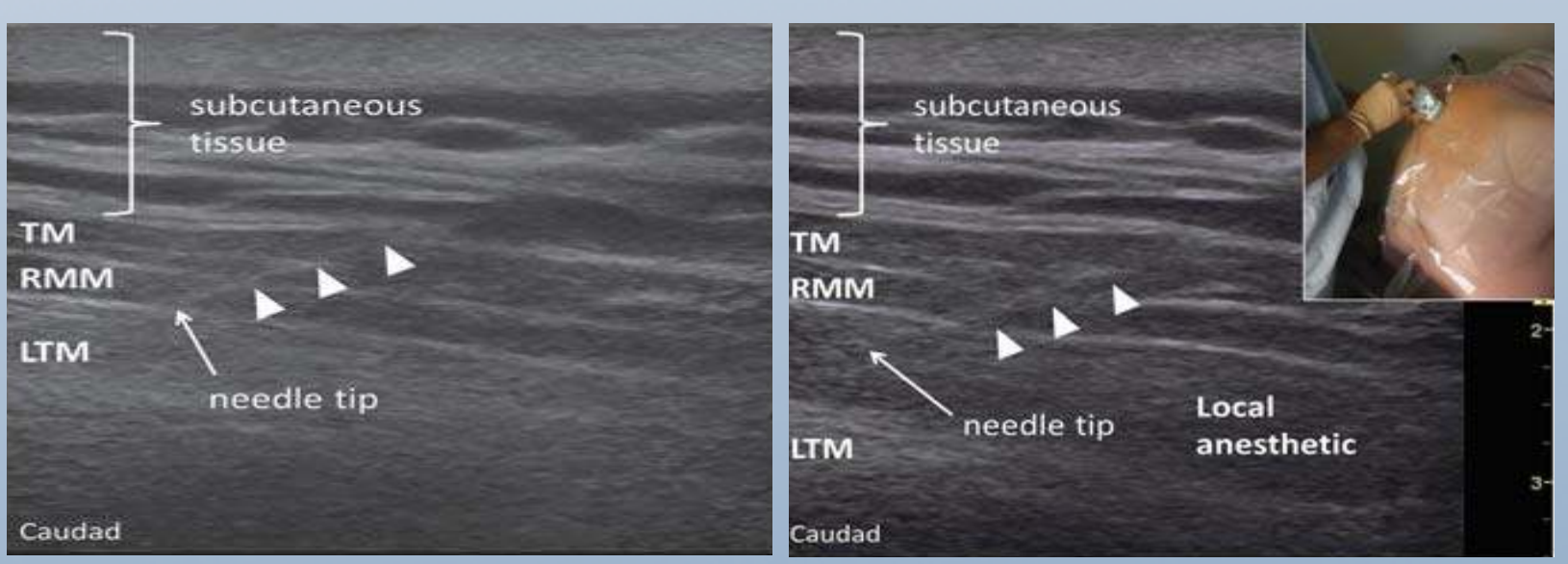

FIGURE 1. Source: Forero M, et al. The Erector Spinae Plane Block: A Novel Analgesic Technique in Thoracic Neuropathic Pain. Reg Anesth Pain Med. 2016 Sep-Oct;41(5):621-7

\section{CASE REPORT}

Our case is about a 41 years old woman that developed a CPTP after a thoracotomy surgery for left inferior lobectomy (atypical carcinoid lung tumor).

Neuropathic pain in the scar of the tube drainage insertion.

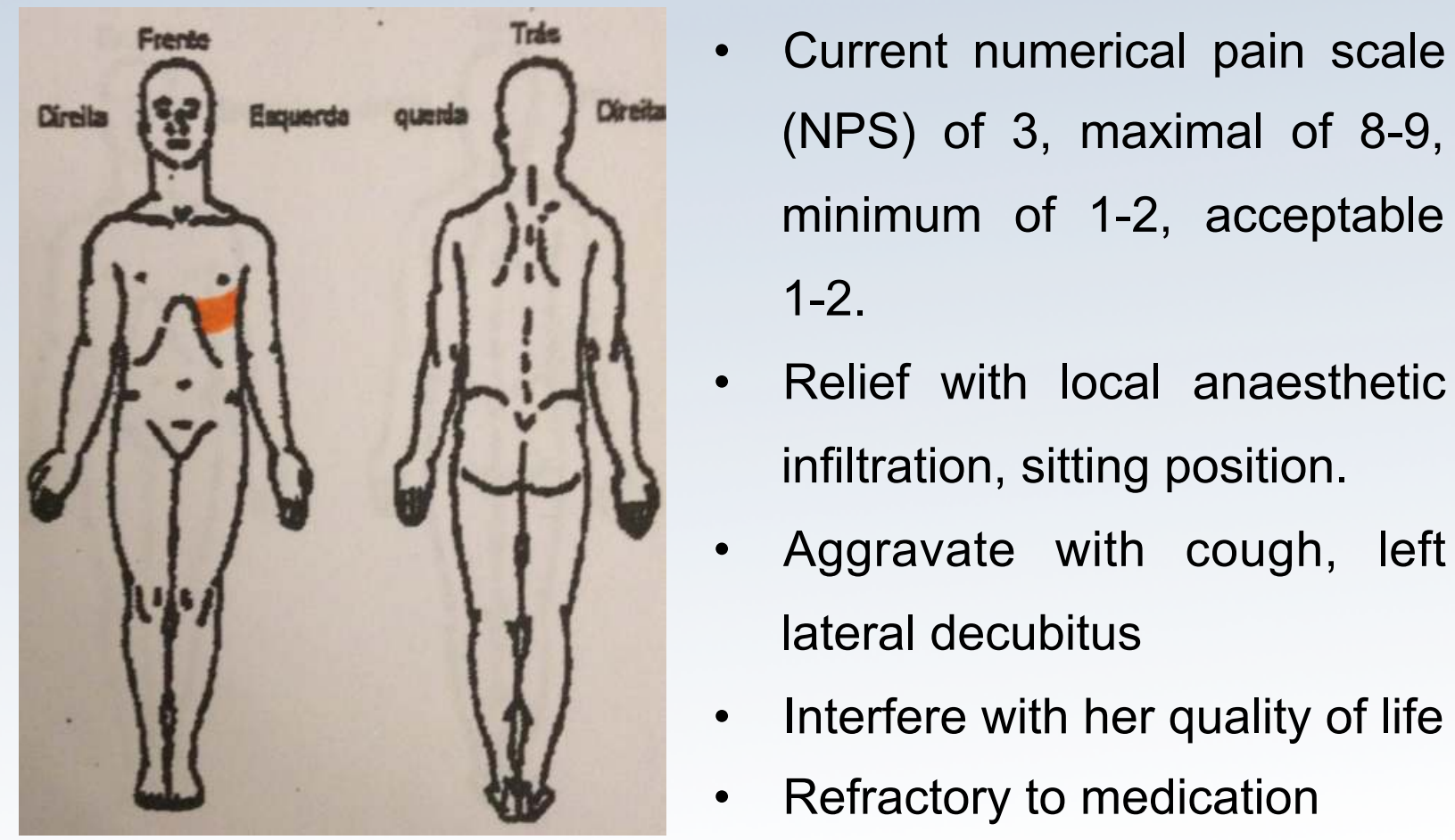

Intercostal blocks, paravertebral block, and acupuncture were performed, all with transient improvement of pain.

USESPB:

- At the level of T5 with triamcinolone $40 \mathrm{mg}$ and ropivacaine $0.375 \%$ in a total of $20 \mathrm{ml}$

- Total abolition of pain was observed for 3 days

- Reduction of T7-T8 infra-mammary paraesthesia for 3 months

- When the pain reappeared

- Less intense

- Maintaining functionality

- NPS current of 2, maximal of 4 , minimum of 1

- After 5 months only worse with touch

\section{DISCUSSION}

The USESPB has proven to be a safe technique with an easily recognizable sonoanatomy that can minor the risk of nerve damage and pneumothorax. Is than relatively safe in patients with coagulopathy.

Placing the catheter in longer treatments is possible.

Is a promising alternative in the treatment of acute PTP.

\section{CONCLUSION}

To prove its effectiveness and safety in all these possible uses this technique must undergo further scientific and clinical research.

\section{REFERENCES}

Mesbah A, Yeung J, Goa F. Pain after Thoracotomy. BJA Education. 2016; 16: 1-7

Bottiger BA, et al. Pain management strategies for thoracotomy and thoracic pain synd. Semin Cardio Vasc Anesth. 2014; 18: 45-56

Forero M, et al. The Erector Spinae Plane Block: A Novel Analgesic Technique in Thoracic Neuropathic Pain. Reg Anesth Pain Med. 2016 Sep-Oct;41(5):621-7 